\title{
Dewatering of Soft Marine Clays by using Electrokinetic Geosynthetics
}

\author{
R.Venkatakrishniah, P. Dayakar, K. Venkat Raman
}

\begin{abstract}
Marine earth is found along the beach front areas of the world. This kind of dirt having uncommon properties like low shear quality and high compressibility. It was discovered that electrokinetic treatment is viable instrument in expanding the quality and expelling the pore water from mud. Electrokinetic geosynthetics (EKG) are recently created material which go about as terminals that readied by joining the electrokinetic marvels with elements of geosynthetics. The target of the work is to think about the dewatering effectiveness of EKG as cathode in marine dirt and the undrained shear quality. The different parameters contemplated are voltage $(6 \mathrm{~V}, 12 \mathrm{~V})$ and distinctive number of electrodes( 1 anode and 2 anode with $10 \mathrm{~cm}$ spacing).The undrained shear quality of soil tests were considered when the treatment. The variety of current and opposition is additionally considered.
\end{abstract}

Keywords - Compressibility, electro kinetic treatment

\section{INTRODUCTION}

Delicate soil like marine earth having high water content brings about releasing of soil particles holding, low bearing limit, low shear quality and high compressibility. Building development is troublesome in delicate soils without changing the qualities[1]-[3]. Dewatering by electrokinetic process is discovered successful in lessening the high water content.

In geo technical application electrokinetic treatment is applied in soil with low penetrability, high pore water and fine grained soils. Electrokinetic treatment is finished by applying electric flow through cathodes.

\section{A. Electro-Osmosis Theory}

Electro-assimilation is where stream of water between the dirt particles is initiated under an applied direct ebb and flow electric field. Electro-assimilation based soil improvement is reasonable for dirt which having net surface negative charge under an applied electric field anions are pulled in towards the anode while cations are pulled in towards cathode[4]-[6].

Customary geosynthetics are utilized in designing fields to do capacities like waste, support, filtration, partition, embodiment and sorption. Elecrokinetic geosynthetics(EKG)

Revised Manuscript Received on October 22, 2019.

R.Venkatakrishniah, Department of Civil Engineering, Bharath Institute of Higher Education and Research, Chennai, India. Email: venkatapec@gmail.com

P. Dayakar, Department of Civil Engineering, Bharath Institute of Higher Education and Research, Chennai , India. Email: dayakarpitti@yahoo.co.in

K. Venkat Raman, Department of Civil Engineering, Bharath Institute of Higher Education and Research, Chennai, India. Email: venkatraman.civil@bharathuniv.ac.in

perform work like dewatering, reinforcing, molding in materials like soil, mucks, slurries, tailings fertilizer. Elecrokinetic geosynthetics have the ability to impact the development of water in soil by electrokinetic implies.

Geosynthetics are principally polymer based material. It very well may be made single or structure blends of woven, non-woven, needle punched, weaved, expelled, or covered materials. Elecrokinetic geosynthetics are framed by incorporation of leading elements within or associated with standard geosynthetic material[7]-[10].

In this examination, Elecrokinetic geosynthetics is utilized as cathode, by framing the geosynthetics as terminals. Elecrokinetic geosynthetics beat the issue of evacuating water by using the waste elements of geosynthetics with the extra favorable position of abusing geosynthetics in electrokinetic implies[11]-[13]. A large portion of Elecrokinetic geosynthetics are having double works at first in dynamic mode which might be of brief span and which is trailed by long haul detached job. In this paper, an investigation of dewatering of marine mud utilizing Galvanized iron (GI) and electrokinetic geosynthetics (EKG) as terminals were utilized.

\section{METHODOLOGY}

A. Soil

Soil is collected from Chennai Port area whose relative properties are shown in Table 1.

\begin{tabular}{|l|l|}
\hline Properties & Values \\
\hline Specific gravity & 2.4 \\
\hline Organic matter content (\%) & 2.7 \\
\hline Liquid limit (\%) & 82 \\
\hline Plastic limit (\%) & 28.5 \\
\hline Plasticity index (\%) & 53.5 \\
\hline Shrinkage limit (\%) & 9 \\
\hline Percentage of clay (\%) & 39.5 \\
\hline Percentage of silt (\%) & 40.5 \\
\hline Percentage of sand (\%) & 20 \\
\hline Optimummoisture content OMC (\%) & 31 \\
\hline Maximum dry density(g/cc) & 1.3 \\
\hline IS soil classification & $\mathrm{MH}$ \\
\hline Undrained shear strength(kN/m $\left.{ }^{2}\right)$ & 3.3 \\
\hline Naturalmoisture content (\%) & 79 \\
\hline
\end{tabular}




\section{B. Test Tanks}

The test tank having dimension $40 \mathrm{~cm} \mathrm{x} 40 \mathrm{~cm}$ x $50 \mathrm{~cm}$ height made of glass of $10 \mathrm{~mm}$ thickness. Holes are provided at the bottom of tank at a spacing of $5 \mathrm{~cm}[14]-[16]$.

\section{Methods}

Water authority plate is given a good ways off of $10 \mathrm{~cm}$ underneath the tank during the procedure. Conductive geosynthetics was set on base of tank. GI cathode is set a ways off of $5 \mathrm{~cm}$ from the base of tank to go about as anode, subsequent to filling the tank with soil with its normal water content .The terminals were then associated utilizing standard adaptable copper wire to a DC unit. Two voltages $6 \mathrm{~V}$ and 12 $\mathrm{V}$ are applied for the examination for term of 3 hours.

Figure. 1 shows the schematic chart of dewatering set up. After the treatment the undrained shear quality from $5 \mathrm{~cm}$ and $15 \mathrm{~cm}$ from anode is resolved[17]-[20].

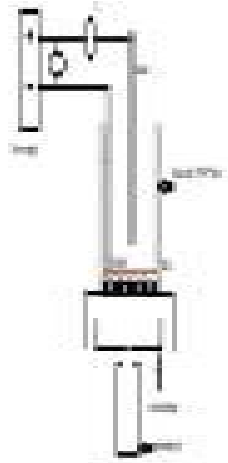

Figure.1.experimental setup

\section{Arrangements of Anode}

Figure 2 shows the arrangement of anode during the treatment. (a) 1 Anode at the center of tank and (b) 2 Anode at a spacing of $10 \mathrm{~cm}[21]-[24]$.

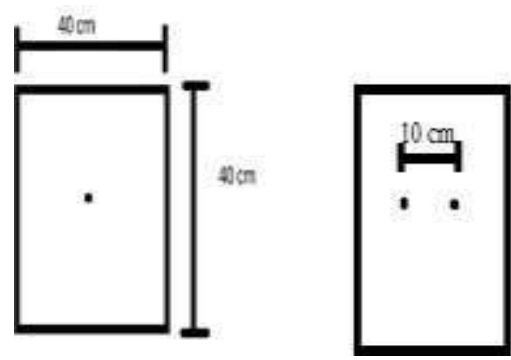

Figure.2.Arrangement of anodes

\section{RESULTS AND DISCUSSIONS}

Cumulative volume of water collected at cathode Figure 3 and Figure 4 shows the cumulative volume of water collected at cathode. As the voltage increases the cumulative volume of water collected also increases. The graph shows the cumulative volume of water increases with voltage and more number of anodes[25]-[30]

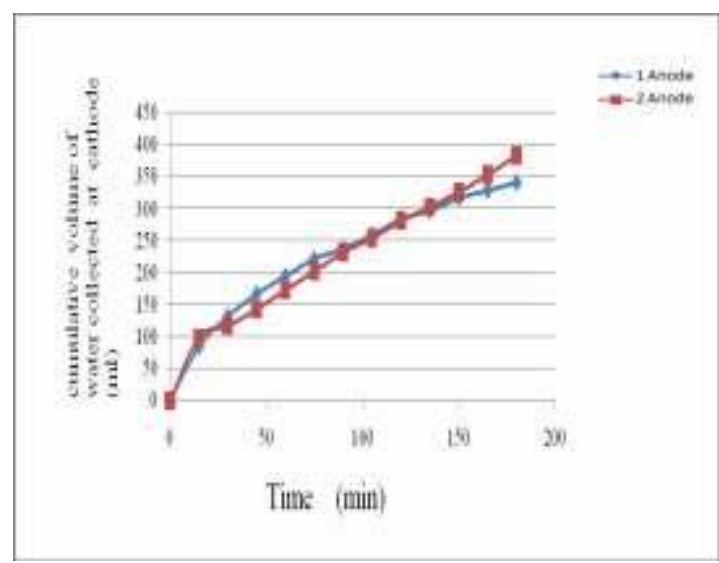

Figure.3.Cumulative volume of water collected at cathode- $6 \mathrm{v}$

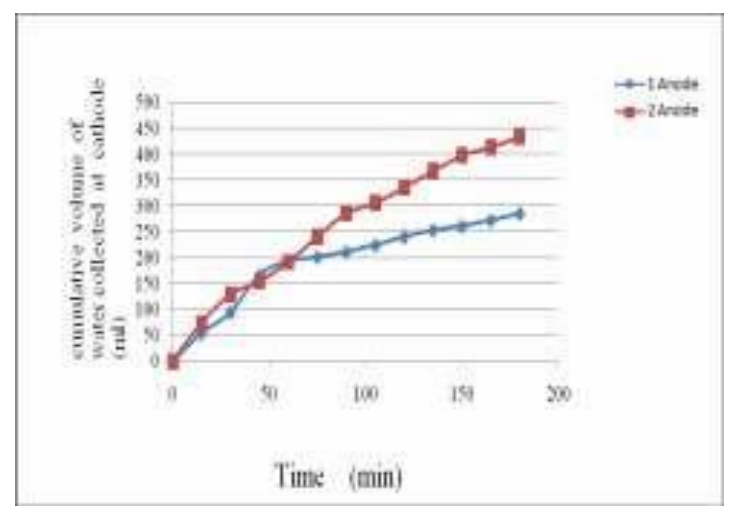

A. Figure.4.Cumulative volume of water collected at cathode- $12 v$

\section{A. Variation of current with time}

Figure 5 and Figure 6 shows the variation of current with time. Current goes on decreases with time. This is due to the decrease in water content[31]-[32].

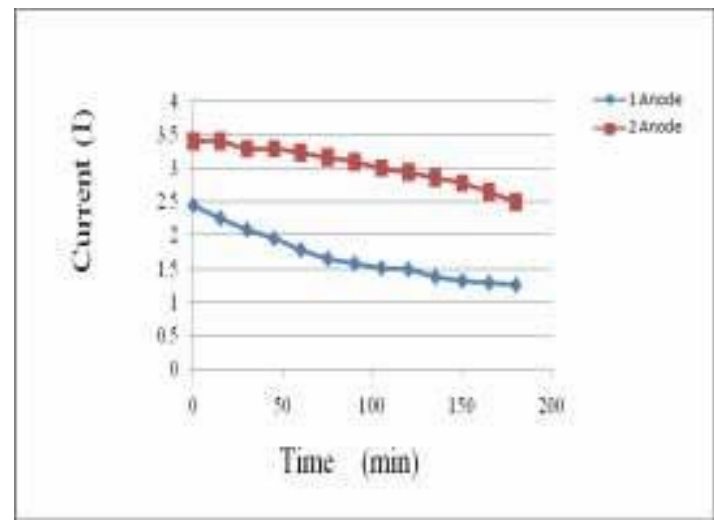

Figure.5.Effect of current with time - $6 \mathrm{v}$ 


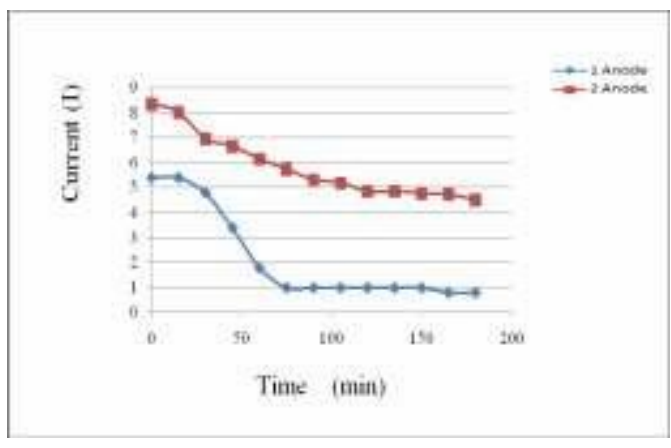

Figure.6.Effect of current with time - 12 v

\section{B. Variation of resistance with time}

Figure 7 and Figure 8 shows the effect of resistance with time. The resistance of soil goes on increases with time

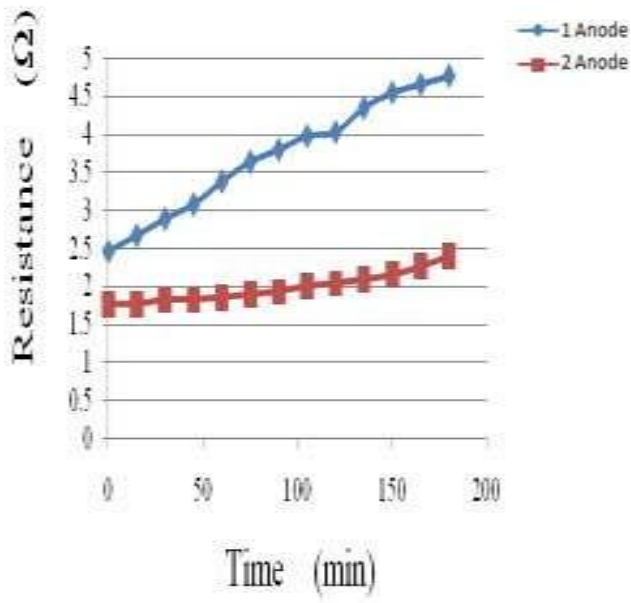

Figure.7.Effect of resistance with time $-6 \mathrm{v}$

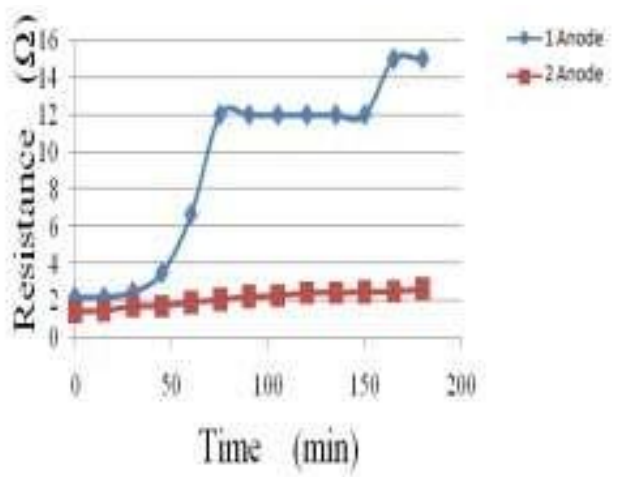

Figure.8.Effect of resistance with time - $12 \mathrm{v}$

\section{Undrained shear strength}

Figure 9 shows the undrained shear strength of clay before and after the treatment. The vane shear strength of soil found to be increased in $5 \mathrm{~cm}$ than $15 \mathrm{~cm}$ from anode .The strength of soil increases the area near anode.

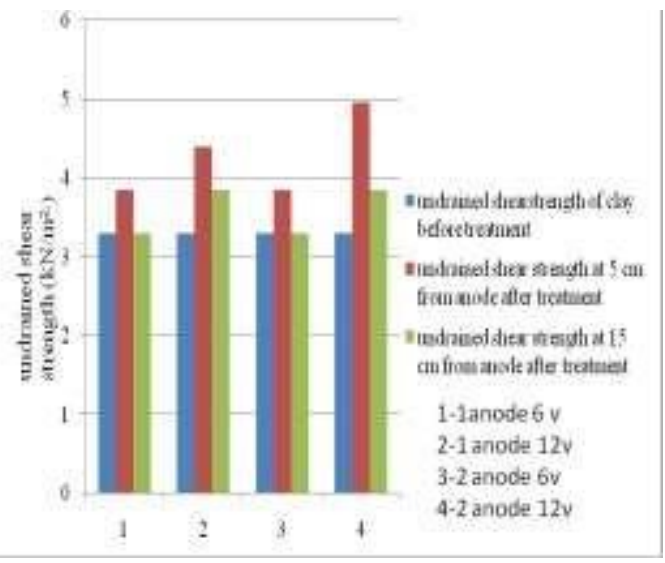

Figure.9.undrained shear strength

\section{CONCLUSION}

From the results presented in this paper electro kinetic geosynthetics are suitable technology for dewatering. The soil near the anode drained out and undrained shear strength of soil near the anode increases and the material become drier. In this study conductive geomembrane is used as cathode using conductors ie, stainless steel mesh[33]-[34]. Geomembrane have functions like filtration, separation, drainage etc. Therefore no filtering units like filter paper is used in this study for filtering the water from clay. The strength of clay is noted after end of treatment and there is increase in strength of soil near the anode. The increase in voltage and number of anodes increase the dewatering process and undrained shear strength of soil. Electro kinetic process decreases the water content near the anode and it is found to be effective tool to remove water from marine clay. The efficiency of process can increase by increasing parameter like time, voltage.

\section{REFERENCES}

1. Iyappan L., Dayakar P., Identification of landslide prone zone for coonoortalukusing spatial technology, International Journal of Applied Engineering Research,V-9,I-22,PP-5724-5732,Y-2014.

2. Kumar J., Sathish Kumar K., Dayakar P.,Effect of microsilica on high strength concrete, International Journal of Applied Engineering Research,V-9,I-22,PP-5427-5432,Y-2014.

3. Dayakar P., Vijay Ruthrapathi G., Prakesh J., Management of bio-medical waste, International Journal of Applied Engineering Research,V-9,I-22,PP-5518-5526,Y-2014.

4. Swaminathan N., Dayakar P., Resource optimization in construction project, International Journal of Applied Engineering Research,V-9,I-22,PP-5546-5551,Y-2014.

5. Venkat Raman K., Dayakar P., Raju K.V.B.,An experimental study on effect of cone diameters in penetration test on sandy soil, International Journal of Civil Engineering and Technology,V-8,I-8,PP-1581-1588,Y-2017.

6. Saritha B., Chockalingam M.P.,Photodradation of malachite green DYE using TIO2/activated carbon composite,International Journal of Civil Engineering and Technology,V-8,I-8,PP-156-163,Y-2017

7. Shendge R.B., Chockalingam M.P., Saritha B., Ambica A.,Swat modelling for sediment yield: A case study of Ujjani reservoir in Maharashtra, India,International Journal of Civil Engineering and Technology,V-9,I-1,PP-245-252,Y-2018

8. Chockalingam M.P., Balamurgan V.,Modernisation of an existing urban road-sector in Chennai, a case study report,International Journal of Civil Engineering and Technology,V-8,I-8,PP-1457-1467,Y-2017 
9. Saritha B., Chockalingam M.P.,Adsorption study on removal of basic dye by modified coconut shell adsorbent, International Journal of Civil Engineering and Technology,V-8,I-8,PP-1370-1374,Y-2017

10. Saritha B., Chockalingam M.P.,Adsorptive removal of heavy metal chromium from aqueous medium using modified natural adsorbent,International Journal of Civil Engineering and Technology,V-8,I-8,PP-1382-1387,Y-2017

11. Chockalingam M.P., Palanivelraja S.,Retrospective analysis of a theoretical model used for forecasting future air quality near the north Chennai thermal power plant,International Journal of Civil Engineering and Technology,V-8,I-8,PP-1457-1467,Y-2017

12. Saritha B., Chockalingam M.P.,Photodegradation of methylene blue dye in aqueous medium by $\mathrm{Fe}-\mathrm{AC} / \mathrm{TiO} 2$ Composite,Nature Environment and Pollution Technology,V-17,I-4,PP-1259-1265,Y-2018

13. Shendge R.B., Chockalingam M.P., Kaviya B., Ambica A.,Estimates of potential evapotranspiration rates by three methods in upper Bhima Basin, In Maharashtra, India,International Journal of Civil Engineering and Technology,V-9,I-2,PP-475-480,Y-2018

14. Shendge R.B., Chockalingam M.P.,The soil and water assessment tool for Ujjani Reservoir,International Journal of Mechanical Engineering and Technology,V-9,I-2,PP-354-359,Y-2018

15. Shendge R.B., Chockalingam M.P.,A review on soil and water assessment tool,International Journal of Mechanical Engineering and Technology,V-9,I-2,PP-347-353,Y-2018

16. Sachithanandam P., Meikandaan T.P., Srividya T.,Steel framed multi storey residential building analysis and design,International Journal of Applied Engineering Research,V-9,I-22,PP-5527-5529,Y-2014

17. Meikandaan T.P., Ramachandra Murthy A.,Study of damaged RC beams repaired by bonding of CFRP laminates,International Journal of Civil Engineering and Technology,V-8,I-2,PP-470-486,Y-2017

18. Meikandaan T.P., Ramachandra Murthy A.,Retrofittng of reinforced concrete beams using GFRP overlays,International Journal of Civil Engineering and Technology,V-8,I-2,PP-423-439,Y-2017

19. Meikandaan T.P., Ramachandra Murthy A.,Flexural behaviour of RC beam wrapped with GFRP sheets,International Journal of Civil Engineering and Technology,V-8,I-2,PP-452-469,Y-2017

20. Meikandaan T.P., Murthy A.R.,Experimental study on strengthening of rc beams using glass Fiber,International Journal of Civil Engineering and Technology,V-9,I-11,PP-959-965,Y-2018

21. Meikandaan T.P., Hemapriya M.,Use of glass FRP sheets as external flexural reinforcement in RCC Beam,International Journal of Civil Engineering and Technology,V-8,I-8,PP-1485-1501,Y-2017

22. Saraswathy R., Saritha B.,Planning of integrated satellite township at Thirumazhisai,International Journal of Applied Engineering Research,V-9,I-22,PP-5558-5560,Y-2014

23. Saritha B., Ilayaraja K., Eqyaabal Z.,Geo textiles and geo synthetics for soil reinforcement,International Journal of Applied Engineering Research,V-9,I-22,PP-5533-5536,Y-2014

24. Ambica A., Saritha B., Changring G., Singh N B., Rajen M., Salman Md.,Analysis of groundwater quality in and around Tambaram taluk, Kancheepuram district,International Journal of Civil Engineering and Technology,V-8,I-8,PP-1362-1369,Y-2017

25. Arunya A., Sarayu K., Ramachandra Murthy A., Iyer N.R.,Enhancement of durability properties of bioconcrete incorporated with nano silica,International Journal of Civil Engineering and Technology,V-8,I-8,PP-1388-1394,Y-2017

26. Ilayaraja K., Krishnamurthy R.R., Jayaprakash M., Velmurugan P.M., Muthuraj S.,Characterization of the 26 December 2004 tsunami deposits in Andaman Islands (Bay of Bengal, India),Environmental Earth Sciences,V-66,I-8,PP-2459-2476,Y-2012

27. Ilayaraja K.,Morphometric parameters of micro watershed in Paravanar sub-basin, Cuddalore District,International Journal of Civil Engineering and Technology,V-8,I-8,PP-1444-1449,Y-2017

28. Ilayaraja K., Singh R.K., Rana N., Chauhan R., Sutradhar N.,Site suitability assessment for residential areas in south Chennai region using remote sensing and GIS techniques,International Journal of Civil Engineering and Technology,V-8,I-8,PP-1468-1475,Y-2017

29. Ilayaraja K., Reza W., Kumar V., Paul S., Chowdhary R.,Estimation of land surface temperature of Chennai metropolitan area using Landsat images,International Journal of Civil Engineering and Technology,V-8,I-8,PP-1450-1456,Y-2017

30. Chitra R.,Experimental study on beam using steel fiber and latex,International Journal of Civil Engineering and Technology,V-8,I-8,PP-1395-1403,Y-2017

31. Chitra R.,Analysis of traffic and management at Kovilambakkam intersection,International Journal of Civil Engineering and Technology,V-8,I-8,PP-1433-1443,Y-2017
32. Aswathy M.,Experimental study on light weight foamed concrete,International Journal of Civil Engineering and Technology,V-8,I-8,PP-1404-1412,Y-2017

33. Aswathy M.,Wastewater treatment using constructed wetland with water lettuce (Eichornia Crasipies),International Journal of Civil Engineering and Technology,V-8,I-8,PP-1413-1421,Y-2017

34. Kiruthiga K., Anandh K.S., Gunasekaran K, Assessment of influencing factors on improving effectiveness and productivity of construction engineers, 2015, International Journal of Applied Engineering Research, V - 10,I -17,p -13849-13854.

\section{AUTHORS PROFILE}

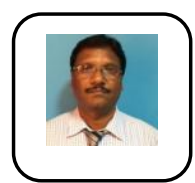

R.Venkatakrishniah Associate Professor, Department of Civil Engineering, Bharath Institute of Higher Education and Research, Chennai, India.

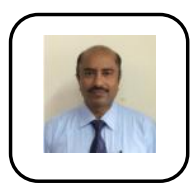

P. Dayakar Associate Professor, Department of Civi Engineering, Bharath Institute of Higher Education and Research, Chennai , India.

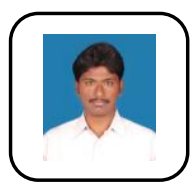

K. Venkat Raman Assistant Professor, Departmen of Civil Engineering, Bharath Institute of Higher Education and Research, Chennai, India. 